\title{
Unusual Case of Obstructive Jaundice
}

\author{
Rajesh Essrani ${ }^{1}$, Eric Nellis ${ }^{2}$, Patrick Hickey ${ }^{2}$, Hiral Shah ${ }^{2}$ \\ 1. Internal Medicine, Lehigh Valley Health Network, Allentown, USA 2. Gastroenterology, Lehigh Valley Health \\ Network, Allentown, USA
}

Corresponding author: Rajesh Essrani, raj1_essrani@hotmail.com

\begin{abstract}
Most malignant obstructive jaundice arises from primary periampullary tumors and rarely from metastatic cancer of the head and neck. A 60-year-old male was diagnosed with obstructive jaundice due to metastatic squamous cell carcinoma of the tonsil. Only 12 cases of small bowel metastasis from the head and neck have been reported. Most of them originate from laryngeal squamous cell carcinoma, and only one case reported tonsillar cancer metastasizing to the ileum. Our case is the first one, to the best of our knowledge, to illustrate tonsillar cancer with metastasis to the duodenum causing obstructive jaundice.
\end{abstract}

Categories: Internal Medicine, Medical Education, Gastroenterology Keywords: obstructive jaudice, head and neck cancer, duodenum

\section{Introduction}

Most malignant obstructive jaundice stems from primary periampullary tumors, such as the pancreas, duodenum, distal common bile duct, and structures of the ampullary complex. Small bowel metastases from the head and neck are very rare. Autopsy studies showed that the most common sites of metastases in head and neck cancer carcinoma are the lungs (72\%), liver (38.6\%), kidney (21\%), adrenal (21\%), bone (23\%), and, rarely, the heart (12\%) and small intestine (7\%) [1]. The incidence of tonsillar cancer, a subtype of head and neck cancers has increased by four times in the United States over the last few decades due to human papillomavirus (HPV) infections and smoking [2]. Tonsillar carcinoma usually metastasizes locally to the cervical lymph nodes [3]. Early stage cancers rarely have distal metastasis but advanced stage cancers can metastasize beyond the cervical lymph nodes [4]. It spreads through the lymphatic and/or vascular channels [5]. We present an unusual case of obstructive jaundice secondary to metastatic tonsillar cancer to the duodenum.

Parts of this article are based on a poster: Rajesh Essrani MD, Eric Nellis MD, Patrick Hickey DO, Hiral Shah MD. Unusual Case of Obstructive Jaundice. World Congress of Gastroenterology at ACG; October 2017.

Received 02/04/2019 Review began 02/17/2019 Review ended 02/17/2019 Published 02/19/2019

๑) Copyright 2019 Essrani et al. This is an open access article distributed under the terms of the Creative Commons Attribution License CC-BY 3.0, which permits unrestricted use, distribution, and reproduction in any medium, provided the original author and source are credited.

\section{Case Presentation}

A 60-year-old male with a remote history of tonsillar squamous cell cancer (SCC) treated with chemoradiation presented with a three-day history of new-onset epigastric pain radiating to his back, which was associated with nausea and vomiting. He had a remote smoking history but no alcohol intake. Three months before this presentation, he was found to have metastatic SCC in the jejunum, which was treated with curative resection.

In addition to his severe pain, the patient noted a 14-pound weight loss over the past three weeks due to his symptoms of anorexia with nausea and vomiting. On clinical examination, vital signs were stable; icterus was present. Abdominal exam was very tender to palpitation in the epigastric region but with normal bowel sounds. He had multiple abnormalities in his liver function panel, including aspartate aminotransferase (AST) - $160 \mathrm{U} / \mathrm{L}$, alanine aminotransferase (ALT) - $218 \mathrm{U} / \mathrm{L}$, alkaline phosphatase - $281 \mathrm{U} / \mathrm{L}$, and total bilirubin - $3.0 \mathrm{mg} / \mathrm{dl}$. Lipase was also markedly elevated at $10304 \mathrm{U} / \mathrm{L}$. Right upper quadrant ultrasound showed biliary sludge. Computed tomography (CT) abdomen with contrast showed gallbladder distention and mild prominence of the intra-and extrahepatic bile duct (Figure 1). 


\section{Cureus}

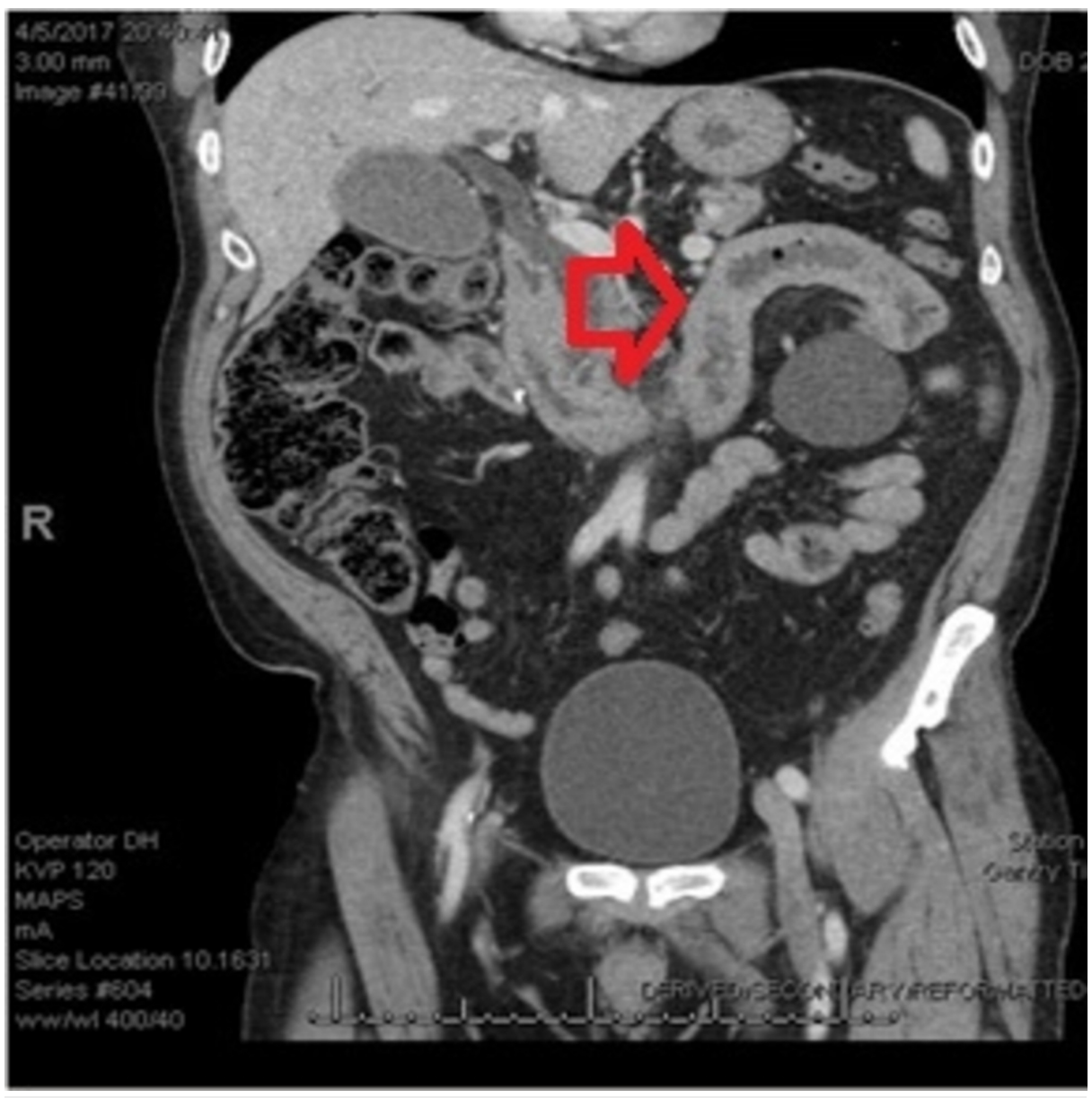

FIGURE 1: CT abdomen-pelvis showing thickening of the duodenum and proximal small bowel

computed tomography (CT)

Magnetic resonance imaging (MRI) abdomen showed a double duct sign (Figure 2). 


\section{Cureus}

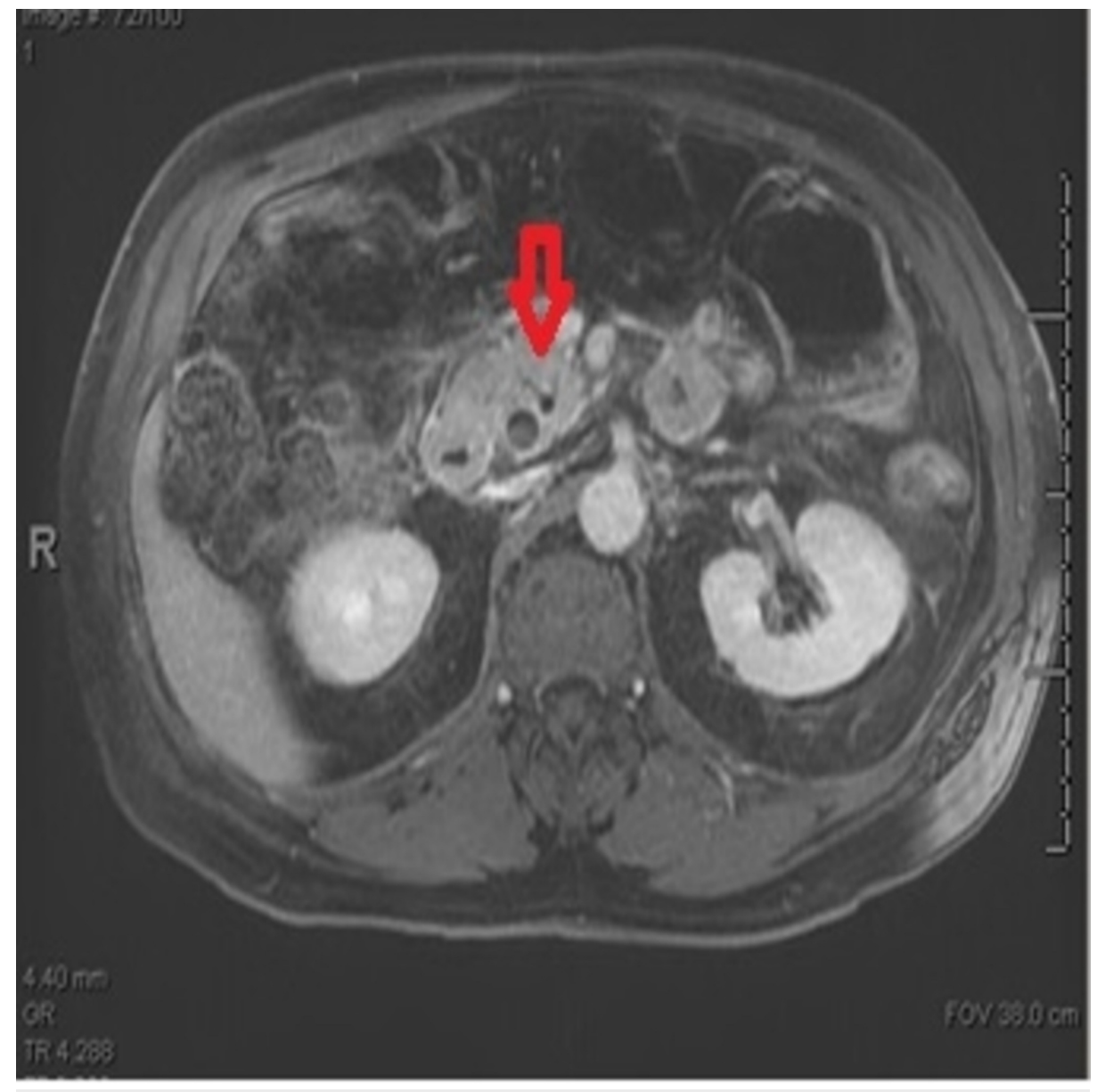

FIGURE 2: MRI abdomen showing double duct sign

magnetic resonance imaging (MRI)

He underwent esophagogastroduodenoscopy (EGD), which showed infiltrative thickening of the duodenal bulb and the second and third portions of the duodenum (Figure 3). 


\section{Cureus}

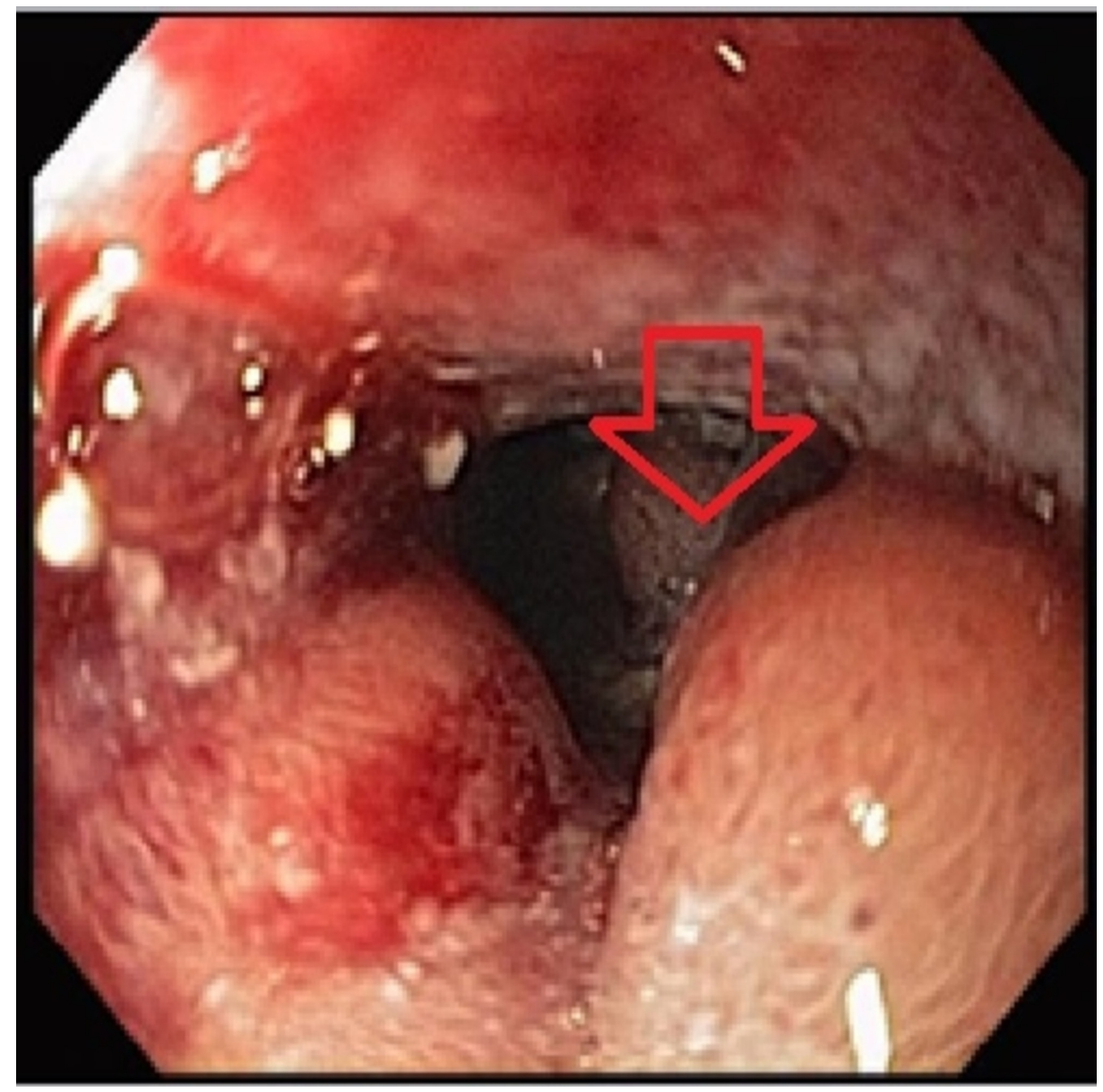

FIGURE 3: EGD showing infiltrative thickening of the duodenal bulb

esophagogastroduodenoscopy (EGD)

Multiple biopsies were taken, and he underwent endoscopic retrograde cholangiopancreatography (ERCP) with biliary stent and drain placement. His abdominal pain improved significantly and was discharged in a stable condition. Pathology of the biopsied mass was consistent with metastatic squamous cell carcinoma of the tonsil.

\section{Discussion}

Obstructive jaundice can be caused by a variety of etiologies, which include either primary or metastatic neoplasm, choledocholithiasis, biliary strictures, parasites, primary sclerosing cholangitis, and cystic duct stones.

Head and neck cancer comprise a variety of cancers with squamous cell carcinoma (HNSCC) being the most common. Risk factors for cancer include smoking, HPV infection, betel nut chewing, radiation exposure, vitamin deficiencies, periodontal disease, immunosuppression, and other environmental and occupational exposures. The clinical presentation depends upon the primary site, distant metastatic site, and exposure to various risk factors. Small bowel metastasis from HNSCC, as any other SCC distant metastasis, results from hematogenous dissemination of the disease and represents florid micrometastasis from the primary tumor [6].

The most common presentation of the head and neck cancer metastasizing to the small bowel is gastrointestinal bleeding, perforation, and gastric outlet obstructive symptoms but, rarely, they might develop obstructive jaundice.

This patient had a history of tonsillar SCC with metastasis to the jejunum, so suspicion was very high for SCC metastasis. Only 12 cases of small bowel metastasis from the head and neck have been reported. Most of them originate from laryngeal SCC, and only one case reported tonsillar cancer metastasizing to the ileum [7]. Our case is the first one to illustrate tonsillar cancer with metastasis to the duodenum causing obstructive jaundice [8]. Diagnosis is made through endoscopic biopsy. 


\section{Conclusions}

During a review of the literature, no previous case reporting tonsillar cancer with metastasis to the duodenum causing obstructive jaundice was found. The diagnosis was made through an endoscopic biopsy. A patient with an obstructive jaundice feature and a history of cancer should raise the suspicion of metastatic cancer and should receive appropriate workup and treatment.

\section{Additional Information \\ Disclosures}

Human subjects: Consent was obtained by all participants in this study. Conflicts of interest: In compliance with the ICMJE uniform disclosure form, all authors declare the following: Payment/services info: All authors have declared that no financial support was received from any organization for the submitted work. Financial relationships: All authors have declared that they have no financial relationships at present or within the previous three years with any organizations that might have an interest in the submitted work. Other relationships: All authors have declared that there are no other relationships or activities that could appear to have influenced the submitted work.

\section{References}

1. O'Brien PH, Carlson R, Steubner EA Jr, Staley CT: Distant metastases in epidermoid cell carcinoma of the head and neck. Cancer. 1971, 27:304-307. 10.1002/1097-0142(197102)27:2<304::AIDCNCR2820270209>3.0.CO;2-1

2. Frisch $M$, Hjalgrim $H$, Jaeger AB, Biggar RJ: Changing patterns of tonsillar squamous cell carcinoma in the United States. Cancer Causes Control. 2000, 11:489-495. 10.1023/A:1008918223334

3. Okura M, Aikawa T, Sawai NY, Iida S, Kogo M: Decision analysis and treatment threshold in a management for the N0 neck of the oral cavity carcinoma. Oral Oncol. 2009, 45:908-911. 10.1016/j.oraloncology.2009.03.013

4. Banerjee S KD, Mukherjee M, Maiti PK: Early stage squamous cell carcinoma of the tonsil presenting with multiple organ metastases including skin and brain after successful local treatment. J Cancer Metastasis Treat. 2015, 1:31-33. 10.4103/2394-4722.152761

5. Irani S: Distant metastasis from oral cancer: a review and molecular biologic aspects . J Int Soc Prev Community Dent. 2016, 6:265-271. 10.4103/2231-0762.186805

6. Buyukcelik A, Ensari A, Sarioglu M, Isikdogan A, Icli F: Squamous cell carcinoma of the larynx metastasized to the ampulla of Vater. Report of a case. Tumori. 2003, 89:199-201. 10.1177/030089160308900219

7. Shah JP, Lydiatt W: Treatment of cancer of the head and neck. CA Cancer J Clin. 1995, 45:352-368. 10.3322/canjclin.45.6.352

8. Dwivedi RC, Kazi R, Agrawal N, et al.: Comprehensive review of small bowel metastasis from head and neck squamous cell carcinoma. Oral Oncol. 2010, 46:330-335. 10.1016/j.oraloncology.2010.01.013 